\title{
An overview of human prion diseases
}

\author{
Muhammad Imran $^{1}$ and Saqib Mahmood ${ }^{2^{*}}$
}

\begin{abstract}
Prion diseases are transmissible, progressive and invariably fatal neurodegenerative conditions associated with misfolding and aggregation of a host-encoded cellular prion protein, $\operatorname{Pr} P^{C}$. They have occurred in a wide range of mammalian species including human. Human prion diseases can arise sporadically, be hereditary or be acquired. Sporadic human prion diseases include Cruetzfeldt-Jacob disease (CJD), fatal insomnia and variably proteasesensitive prionopathy. Genetic or familial prion diseases are caused by autosomal dominantly inherited mutations in the gene encoding for $\operatorname{PrP}^{C}$ and include familial or genetic CJD, fatal familial insomnia and Gerstmann-SträusslerScheinker syndrome. Acquired human prion diseases account for only $5 \%$ of cases of human prion disease. They include kuru, iatrogenic CJD and a new variant form of CJD that was transmitted to humans from affected cattle via meat consumption especially brain. This review presents information on the epidemiology, etiology, clinical assessment, neuropathology and public health concerns of human prion diseases. The role of the PrP encoding gene (PRNP) in conferring susceptibility to human prion diseases is also discussed.
\end{abstract}

Keywords: Prions, Prion diseases, PRNP, TSE, CJD

\section{Background}

Prion diseases are transmissible protein misfolding disorders in which misfolding of a host-encoded prion protein (PrP) occurs. PrP is a 253 amino acids (aa) protein. The first $22 \mathrm{~N}$-terminal aa are removed from PrP after its transport to endoplasmic reticulum, while the last 23 C-terminal aa are cleaved off after the addition of glycosylphosphatidylinositol (GPI) anchor, which helps the protein to attach to the outer surface of cell membranes. PrP may exist in two forms: a normal cellular prion protein designated as $\operatorname{PrP}^{C}$ and a pathogenic misfolded conformer designated as $\operatorname{PrP}^{\mathrm{Sc}}$. Both $\operatorname{PrP}^{\mathrm{C}}$ and $\operatorname{Pr} \mathrm{P}^{\mathrm{Sc}}$ conformers are encoded from the same sequence of the $16 \mathrm{~kb}$ single copy PRNP gene that is positioned on the short (p) arm of human chromosome 20 (20p13), from base pairs 4,666,796-4,682,233. The human PRNP contains two exons with the second one carrying the whole open reading frame. The abnormal $\mathrm{PrP}^{\mathrm{Sc}}$ isoform differs from the normal $\mathrm{PrP}^{\mathrm{C}}$ isoform in secondary and tertiary structure, but not in primary amino acids sequence. $\operatorname{PrP}^{C}$ is predominantly rich in alpha helical contents, while $\mathrm{PrP}^{\mathrm{Sc}}$ is predominantly rich in beta sheet contents [1-5]. This conformational discrepancy renders the

\footnotetext{
* Correspondence: medgen@uhs.edu.pk

${ }^{2}$ Department of Human Genetics and Molecular Biology, University of Health Sciences (UHS), Khayaban-e-Jamia Punjab, Lahore 54600, Pakistan Full list of author information is available at the end of the article
}

$\mathrm{PrP}^{\mathrm{Sc}}$ isoform extremely resistant to proteolysis and degradation by conventional means of chemical and physical decontamination or disinfection. In contrast to $\operatorname{PrP}^{\mathrm{Sc}}, \mathrm{PrP}^{\mathrm{C}}$ is soluble in non-denaturing detergents and is completely degraded by proteases $[1,3]$.

The superscript $(\mathrm{Sc})$ has been used to refer to scrapie, the first and the most ancient animal Transmissible Spongiform Encephalopathy (TSE). Many authors also use superscripts other than $(\mathrm{Sc})$ to distinguish normal and pathogenic (disease-causing) isoforms. These include (res) for resistant and (Dis) for disease. An abbreviated name of a prion disease can also be used as superscript to point out the origin of the pathogenic isoform i.e. $\operatorname{PrP}^{\mathrm{Sc}}$ or $\mathrm{PrP}^{\mathrm{CJD}}$. The pathogenic conformers are simply called prions (the infectious protein particles) [3].

According to seeding-nucleation model, the preexisting or acquired $\mathrm{PrP}^{\mathrm{Sc}}$ oligomers catalyze the conversion of $\operatorname{PrP}^{\mathrm{C}}$ molecules into $\mathrm{PrP}^{\mathrm{Sc}}$ fibrils the breakage of which provides more $\mathrm{PrP}^{\mathrm{Sc}}$ templates for the conversion process. The process of prion propagation in the brain results in the pathogenesis of prion diseases [6]. Sixteen different variants of prion disease have been reported so far: nine in humans and seven in animals. The etiology, host range and year of description for these disease variants are given in Table 1. In the present review, a brief description of human prion diseases is provided. 
Table 1 Etiology of prion disease

\begin{tabular}{|c|c|c|c|c|}
\hline \multicolumn{5}{|c|}{ Animal prion diseases } \\
\hline Disease & Host & Etiology & Year of Description & References \\
\hline Scrapie & Sheep, Goats & Infection with Prions of unknown origin & Mid 18th century & {$[7,8]$} \\
\hline$\overline{T M E}$ & Mink & Infection with Prions of either sheep or cattle origin & 1947 & {$[8-10]$} \\
\hline CWD & Cervids & Infection with Prions of unknown origin & 1967 & {$[8,10,11]$} \\
\hline$\overline{B S E}$ & Cattle & Infection with Prions of unknown origin & 1986 & {$[8,12]$} \\
\hline EUE & Nyala, Kudu & Infection with Prions of BSE origin & 1986 & {$[8,10,13,14]$} \\
\hline$\overline{\text { FSE }}$ & Cats & Infection with Prions of BSE origin & 1990 & {$[8,10,15]$} \\
\hline $\mathrm{NHP}$ & Lemurs & Infection with Prions of BSE origin & 1996 & {$[8,10,16]$} \\
\hline \multicolumn{5}{|c|}{ Human prion diseases } \\
\hline Disease & Host & Etiology & Year of Description & References \\
\hline Kuru & Human & Ritualistic Cannibalism or "Transumption" & 1957 & {$[17]$} \\
\hline SCJD & Human & Spontaneous $\operatorname{PrPC} \rightarrow \mathrm{PrP}^{\mathrm{SC}}$ conversion or somatic mutation & 1920 & {$[18,19]$} \\
\hline $\mathrm{f} / \mathrm{gCJD}$ & Human & Mutations in PRNP & 1924 & {$[20]$} \\
\hline GSS & Human & Mutations in PRNP & 1936 & {$[21]$} \\
\hline$\overline{\mathrm{iCJD}}$ & Human & Infection with Prions of human origin by cadaveric corneal grafts, hGH or dura mater & 1974 & {$[22]$} \\
\hline $\mathrm{FFI}$ & Human & PRNP haplotype $178 \mathrm{~N}-129 \mathrm{M}$ & 1986 & {$[23]$} \\
\hline VCJD & Human & Infection with Prions of BSE origin & 1996 & {$[24]$} \\
\hline$\overline{\mathrm{sFl}}$ & Human & Spontaneous $\mathrm{PrP}^{\mathrm{C}} \rightarrow \mathrm{PrP}^{\mathrm{SC}}$ conversion or somatic mutation & 1999 & {$[25]$} \\
\hline VPSPr & Human & Spontaneous $\mathrm{PrP}^{\mathrm{C}} \rightarrow \mathrm{PrP}^{\mathrm{SC}}$ conversion or somatic mutation & 2008 & {$[26]$} \\
\hline
\end{tabular}

\section{Sporadic Cruetzfeldt-Jacob disease (sCJD)}

Sporadic Cruetzfeldt-Jacob disease accounts for $85 \%$ of all CJD cases with annual worldwide incidence of 1-2 cases/million population [27]. It occurs equally in both sexes with a peak age of onset between 55 and 75 years. Some younger (below 20 years) and oldest (above 90 years) cases have also been reported. Clinical symptoms include rapidly progressive dementia, cerebellar dysfunction including muscle incoordination, and visual, speech and gait abnormalities. Dementia is the major symptom followed by spontaneous or induced myoclonia. During the disease course, symptoms of pyramidal and extrapyramidal dysfunction with reflexes, tremors, spasticity and rigidity, and behavioral changes with agitation, confusion and depression may also be observed. At the end of the disease course, most of patients go into a state of akinetic mutism (they become unresponsive to exterior stimuli) $[28,29]$.

The presence of spongiform changes and sparse $\mathrm{PrP}^{\mathrm{Sc}}$ distribution in CNS of SCJD patients are the hallmark of neuropathology of the disease. The deposits of amyloid plaques may also be noticed in $5-10 \%$ of cases $[28,30]$. On the basis of clinicopathological findings, different variants of SCJD have been described. Amaurotic or Heindenhain variant is characterized by rapidly progressive dementia, myoclonus, visual disturbances such as hallucinations, visual agnosia and cortical blindness, and short disease duration; Brownell and Oppenheimer variant is characterized by an early and predominant cerebellar ataxia and relatively late dementia; the thalamic form is characterized by dementia and movement disorders; while the panencephalic Japanese variant is characterized by high amount of cells in CSF, profound damage of the white matter and a very slow disease course $[28,29,31,32]$.

On the basis of clinical, biological, electrophysiological and neuropathological findings, SCJD cases can be classified as possible, probable or definite cases. Possible cases are characterized by rapidly progressive dementia accompanied by at least two of the following symptoms: myoclonus, cerebellar or visual symptoms, pyramidal or extrapyramidal signs, akinetic mutism and disease course of less than 2 years. Possible cases are considered probable cases when they reveal a characteristic periodic EEG or increased levels of 14-3-3 protein in CSF [29]. Definite cases are defined by the presence of spongiform changes or $\operatorname{PrP}^{\mathrm{Sc}}$ reactivity in brain. Notably, sCJD symptoms may also be seen in disorders like Alzheimer's disease, diffuse Lewy body disease or frontal dementia, paraneoplastic syndrome, tumor or stroke and in disorders with toxic, nutrition, metabolism or infection-related causes. Differential diagnosis for possible and probable cases of sCJD is, therefore, needed. Computed tomography (CT) may reveal signal of mild brain atrophy in some cases. The use of cranial magnetic resonance imaging (MRI) is helpful in detecting brain atrophy and, in more than $50 \%$ of cases, may reveal high signals on T2, flair or diffusion-weighted sequences in 
basal ganglia or in cerebral or cerebellar cortex [29]. Almost all sCJD cases show altered electroencephalographic (EEG) signals. Slow wave activity remains constant and deteriorates with the progression of the disease. Pseudo-periodic sharp wave complexes of 1 Hertz are characteristic of EEG in SCJD cases. To overcome the transient nature of periodic sharp wave complexes, repeated EEG recordings are required [29,33].

The clinicopathological and molecular phenotypes of SCJD are greatly influenced by variations in PRNP. PRNP polymorphisms in regulatory as well as coding sequences have been associated with predisposition to the disease development [34-36]. Homozygosity at M129V polymorphism is a strong risk factor for the development of sCJD [36,37]. In Japanese, homozygosity at another PRNP polymorphism E219K is also a risk factor for the development of sCJD [38,39]. E219K has been found in only Asian and Pacific populations which are more homozygous for methionone at codon 129 as compared to Western populations [27,40]. Inefficient interaction between heterologous $\operatorname{PrP}^{\mathrm{C}}$ molecules encoded from distinct PRNP alleles (129 M and $129 \mathrm{~V})$ may restrict the conversion of $\operatorname{PrP}^{\mathrm{C}}$ into $\operatorname{PrP}^{\mathrm{Sc}}$. Any constraint in the process of prion propagation is assumed to slow down the progression of the disease [36]. The clinical phenotypic heterogeneity seen in SCJD cases can be attributed to different prion strains. A strain is biochemically defined by pattern and ratios of $\mathrm{PrP}^{\mathrm{Sc}}$ fragments on Western blot. Three M129V genotypes (129 $\mathrm{MM}, 129 \mathrm{MV}$ and $129 \mathrm{VV}$ ) and 2 strain types (type 1 and type 2) can be coupled into 6 combinations (MM1, MV1, VV1, MM2, MV2 and VV2) which correspond very well to different clinical phenotypes of sCJD. On the basis of these 6 combinations, three different strain classification systems have been proposed [32,41-43].

\section{Fatal familial insomnia (FFI)}

Previously known as thalamic dementia but renamed in 1986 as fatal familial insomnia (FFI) is an autosomal dominantly inherited human prion disease. FFI is caused by a PRNP mutation D178N linked to methionine of the PRNP polymorphism M129V. When linked to valine at the codon 129 , the same mutation leads to a diverse phenotype of f/gCJD $[23,44,45]$. So far, almost 100 cases of FFI in almost 40 families have been reported from Italy, Germany, Austria, Spain, UK, France, Finland, the United States, Australia, Japan, China, and Morocco [46].

FFI occurs equally in men and women without any significant difference between $129 \mathrm{MM}$ and $129 \mathrm{MV}$ genotypes. However, the disease duration may be significantly shorter in $129 \mathrm{MM}$ subjects. The FFI cases present between 20 and 72 years with an average of 49 years and may live after the disease onset for 8-72 months with an average of 18.4 months. Clinical symptoms include insomnia or disrupted sleep. Myoclonus, ataxia, dysarthria, dysphagia, and pyramidal signs, and autonomic hyperactivation can also be noted. Severity and sequence of clinical symptoms may differ between $129 \mathrm{MM}$ and $129 \mathrm{MV}$ genotypes. Insomnia, myoclonus and autonomic dysfunction are often more severe in 129 MM subjects, while ataxia, dysarthria and seizures often predominate in $129 \mathrm{MV}$ subjects $[28,29,44,45,47]$.

Polysomnography is very useful for the diagnosis of the disease. It provides evidence of insomnia by displaying marked reduction in sleep time and disorderly transition between sleep stages. The $129 \mathrm{MV}$ genotype is known to reduce the severity of these signs of abnormal sleep. In contrast, the $129 \mathrm{MV}$ genotype is associated with more widespread hypometabolism in the thalamus and cingulate cortex as revealed by positron emission tomography (PET). Thus, PET may be another useful tool for the diagnosis of FFI. With later cerebral cortical and cerebellar involvement, neuronal loss and astrogliosis occur predominantly in the anterior and dorsomedian thalamic nuclei in all cases and in the inferior olives in most cases with scant PrP deposition. However, PrP deposits may be more evident in the molecular layer of the cerebellum with a strip like pattern and in the subiculum entorhinal region $[28,29,44,45,47]$.

\section{Sporadic fatal insomnia (sFI)}

A sporadic form of fatal insomnia (sFI) was reported in 1999. The patients showed clinical and neuropathological signs similar to FFI but family history and mutations in PRNP were not evident. All patients were 129 MM homozygotes and biochemical strain typing of these disease subtypes revealed the only difference in the intensity of the unglycosylated fragment of $\mathrm{PrP}^{\mathrm{Sc}}$ type 2; the unglycosylated fragment was under-represented in FFI $[25,45,48]$. So far, near 24 sFI cases all revealing $129 \mathrm{MM}$ homozygosity and propagating $\mathrm{PrP}^{\mathrm{Sc}}$ type 2 have been reported in various countries of the world [49]. sFI is occasionally also referred to as "sCJDMM2 thalamic" but is clinicopathologically sufficiently distinct from sCJDMM2. In SCJDMM2, cerebral cortex is most severely affected rather than thalamus where possibly the circadian rhythms of sleep-wake cycle are controlled $[42,45]$. How the same MM2 $\mathrm{PrP}^{\mathrm{Sc}}$ encodes distinct phenotypes in SCJD and SFI is a matter of concern, indicating that factors additional to the codon 129 genotype and $\operatorname{PrP}^{\mathrm{Sc}}$ type may also be involved in the determination of prion strains. However, MM2 $\mathrm{PrP}^{\mathrm{Sc}}$ conformers associated with sCJD and sFI may show variation in the intensity and size of their fragments by the application of more sensitive 2dimensional electrophoretic separation and improved PK digestion conditions [42]. 
Familial or genetic CJD (f/gCJD)

Familial CJD (fCJD) is associated with dominantly inherited point mutations in PRNP. There is a region of 5 repeats within PrP from residues 51-91 comprised of a nonapeptide PQGGGGWGQ and four tandem octapeptide repeats (PHGGGWGQ) 4 . Insertions of 2-9 octapeptide repeats (2-9-OPRI) and a deletion of 2 octapeptide repeats (2-OPRD) in PRNP are also associated with susceptibility to fCJD. Because more than $50 \%$ of fCJD cases have been reported without a positive family history of the disease, the term "genetic CJD (gCJD)" is now being used more frequently instead of fCJD. There is much variation in the penetrance of different mutations as evidenced by considerable intrafamilial and intragenerational phenotypic variability; sometimes, the disease may skip a generation. The incidence of gCJD is 5-15\% of all CJD cases. Although the familial nature of gCJD is known since 1920s, mutations associated with the disease were first reported in 1989 only 2 years after the cloning of PRNP cDNA [28,29,42,44,47,50]. The frequency of mutations differs worldwide; however, geographical or ethnic clusters of gCJD cases with mutations E200K, I210V, D178N, and V180I have been reported from Israel, Slovakia, Chile, Italy, Spain and Japan $[42,51]$.

Similar to CJD, the clinicopathological phenotype in gCJD largely correlates with the codon 129 genotypes and $\operatorname{PrP}^{\mathrm{Sc}}$ type, and mutations appear to play a role not more than a susceptibility factor. Whether PRNP polymorphisms other than M129V also influence the disease characteristics is unknown. Multiple strains, although yet remain unidentified, may be involved in the pathogenesis of the disease. For some gCJD cases, fragments of $12-18.5 \mathrm{kDa}$ in addition to fragments of 19 and 21 $\mathrm{kDa}$ which characterize $\mathrm{PrP}^{\mathrm{Sc}}$ types 2 and 1 , respectively, can also be found. PRNP mutations may play their part in the pathogenesis of gCJD by i) increasing the propensity of $\operatorname{PrP}^{\mathrm{C}}$ and $\operatorname{PrP}^{\mathrm{M}}$ for aggregation, ii) increasing the retention of aggregated $\operatorname{PrP}$ molecules within secretory pathways, and iii) modulating the intramolecular saltbridge and hydrogen bond interactions. Disturbance in intramolecular interactions is known to project the hydrophobic amino acids outside making the protein insoluble [44]. With increase of every OPR, both the ability of $\operatorname{PrP}^{\mathrm{M}}$ for binding divalent ions such as copper and the severity of clinicopathological phenotype are increased. The biochemical strain typing of gCJD often reveals the underrepresentation of unglycosylated fragments. This is because unglycosylated fragments are more unstable than mono- and diglycosylated fragments and are, therefore, more inefficient in their transport from secretory pathways to the plasma membrane [42,44,52]. Although clinical phenotypes related to most of mutations overlap with those of sCJD [42], the clinical phenotype in gCJD cases carrying the T183A$129 \mathrm{M}$ haplotype is slightly distinctive and incorporates personality changes followed by rapidly progressive dementia, with fronto-temporal features such as aggressive behavior, hyperorality, verbal stereotypes and often parkinsonian signs [53].

\section{Gerstmann-Sträussler-Scheinker syndrome (GSS)}

Autosomal dominant inheritance of PRNP mutations may also lead to another form of human TSE named as Gerstmann-Sträussler-Scheinker Syndrome (GSS). The incidence of GSS is 1 in 100 million of population per year [28]. GSS is characterized by an early onset between 30 and 60 years of age and slow disease progression extended over a period of 3.5-9.5 years. Clinical symptoms which may show intrafamilial and intragenerational variation include cerebellar ataxia, gait abnormalities, dementia, dysarthria, ocular dysmetria, infrequent myoclonus, spastic paraparesis, parkinsonian signs, and hyporeflexia or areflexia in the lower extremities $[28,29]$. However, legs hyperreflexia from an early disease course has recently been seen in a Japanese GSS patient carrying the P102L mutation [54]. In GSS, altered sleep and temperature rhythms may also be noticed [55]. The PRNP polymorphism M129V has been shown to influence the disease phenotype. When linked to V129 allele, P102L, which is the most common cause of GSS, resulted in the predominance of psychiatric signs such as apathy and depression [56]. EEG is rarely diagnostic in GSS. Following PRNP mutations have been shown to cosegregate with GSS: P102L, P105L, A117V, Y145X, Q160X, F198S, Q217R, Y218N, Y226X and Q227X [28,29,57]. Y218N demonstrated clinical criteria for possible Alzheimer disease and possible frontotemporal dementia, with neurofibrillary degeneration on neuropathological profiles, and various $\operatorname{PrP}^{\mathrm{Sc}}$ fragments in the range of $10-80 \mathrm{kDa}$ [58]. In general, neuropathologic features of GSS patients include numerous amyloid plaques, severe to absent spongiform changes, neuronal loss, astrocytic microgliosis, and variable nuerofibrillary tangles $[28,29,59]$.

\section{latrogenic CJD (iCJD)}

Iatrogenic CJD (iCJD) was first described in 1974 in a person who received cadaveric corneal transplant from a patient of CJD [22]. Several cases of human prion disease, since then, have been associated with iatrogenic transmission of CJD by the use of stereotactic intracerebral EEG needles or neurosurgical instruments, cadaveric dura mater grafts and intramuscular injections of contaminated cadaveric pituitary-derived human growth hormone (hGH) and gonadotrophin hormone. The highest proportion of iCJD cases is attributed to treatment with hGH and Lyodura grafts produced by B. 
Braun Melsungen AG of Germany and processed before May 1987. Most of CJD cases linked to treatment with hGH have occurred in France, while those linked to treatment with dura mater grafts have mainly occurred in Japan $[28,29,51,60]$. Between the late 1950s and 1985, about 30,000 children were treated with hGH worldwide, and the overall proportion of CJD cases from the treated population has been estimated to be about 1/ 100. It is believed that the likely $\operatorname{PrP}^{\mathrm{Sc}}$ contamination of pituitary-derived hGH and dura mater grafts resulted from the practice of batch processing. Before the production of recombinant $\mathrm{hGH}$, it was a pharmaceutical practice to process 5,000-20,000 cadaveric pituitary glands in a single batch for the extraction of the hormone. The presence in the batch of a few pituitary glands from unknown CJD cases may be responsible for contamination. With the availability of recombinant $\mathrm{hGH}$ and the initiation of separated processing of individual dura mater grafts since 1987, the probability of occurring future iCJD cases appears to be very low. A peak in the incidence of $\mathrm{iCJD}$ cases with long incubation periods may occur, however [28,29,60].

The clinicopathological features of CJD linked to treatment with hGH resemble with those of kuru. The $129 \mathrm{MM}$ homozygosity is a risk factor and incubation periods may be in the range of 4.5 to over 25 years with a mean of 12 years $[28,29,60,61]$. In contrast, the clinicopathological features of CJD linked to neurografting of dura mater or the use of neurosurgical instruments resemble with those of SCJD. The mean duration of illness is 18 months and the incubation periods may be in the range of 1.5-18 years with a mean of about 6 years. In Japan, the minimum risk of developing $\mathrm{iCJD}$ has been estimated to be approximately $1 / 3000$ Lyodura graft recipients [28,29,60].

\section{Kuru}

Kuru is the first human prion disease that was shown to be transmissible to chimpanzees by intracerebral introduction of brain homogenates from kuru patients [62]. Kuru has occurred exclusively in the Fore linguistic group of Papua New Guinea Eastern Highlands and the neighboring peoples with whom they intermarried. There was a practice among these groups to consume the dead bodies of their relatives as a mark of respect and mourning (ritualistic cannibalism). Women and young children of both sexes were more exposed to the risk material such as brain and viscera than adult men who usually had preferentially to consume muscles. The kuru epidemic killed 1-2\% of the population at its peak. Some villages became even devoid of adult women. With a ban on ritualistic cannibalism in the mid-1950s imposed by Australian authorities, the incidence of the disease started to decline steadily. Kuru was introduced to Western medicine in late 1950 s, although the first case of kuru was observed around 1920. The Western scientists were very soon able to prove ritualistic cannibalism as the etiology of the disease. The older kuru patients who experienced an exposure to the infection before the ban can still be seen. The incubation periods of kuru in such patients would be more than 50 years [27,59,63-65]. Kuru has imposed strong selection pressure in the affected Fore groups on PRNP especially at codons 127 and 129. Heterozygosity at these PRNP codons is a resistance factor for kuru and can be seen with marked prevalence among survivors of the kuru epidemic $[27,65]$.

Kuru has 3 clinical stages namely ambulant (still can walk), sedentary (only can sit up), and terminal (unable to sit up independently). An ill-defined prodromal period characterized by headache and pain usually in the joints of legs may precede these stages. Cerebellar ataxia, tremors and choreiform and athetoid movements are distinctive and prominent clinical signs. Shivering amplifiable by cold was the symptom on the basis of which the disease was named "kuru". The most prominent clinical feature of sCJD, the dementic illness can also occur in some cases but it happens during the final disease stages only. Neuropathological features such as spongiosis, neuronal loss, and astrocytic microgliosis can variably be observed in CNS usually in the grey matter. The $\operatorname{PrP}^{\mathrm{Sc}}$ deposition is observed in CNS only $[59,63]$. The neuropathological property which distinguishes kuru from SCJD is the presence of numerous kuru plaques, spherical bodies with a rim of radiating filaments. Kuru is believed to be caused by the consumption of a sCJD case and experimental transmission studies have shown similarity between the molecular and pathobiological properties of prions causing kuru, sCJD and iCJD [66]. Similar studies have also revealed differences in transmission dynamics, peripheral pathogenesis and the neuropathology properties of kuru and vCJD prions. As both kuru and vCJD are caused by infection via oral route, these differences can be attributed to the strain type rather than the route of infection [63]. However, a recent study showed that $\mathrm{SCJD}, \mathrm{BSE}$ and scrapie agents were evidently different from the kuru agent in incubation time, brain neuropathology, and the lymphoreticular involvement. The authors concluded that "the geographic independence of the kuru agent provides additional reasons to explore causal environmental pathogens in these infectious neurodegenerative diseases" $[67,68]$.

\section{Variant CJD (vCJD)}

The first 10 patients of new variant or simply of variant CJD (nvCJD/vCJD) were reported in April 1996 in UK $[24,60]$. The age of these patients was relatively younger 
between 16 and 39 years and they manifested a predominance of psychiatric symptoms instead of cerebellar ataxia or progressive dementia [60]. About 219 vCJD cases have been reported hitherto from 8 European and 4 non-European countries (USA, Canada, Saudi Arabia, and Japan). The most of vCJD cases (172) have been reported from UK alone [69]. Psychiatric and behavioral symptoms of vCJD may include agitation, aggression, depression, anxiety, apathy, emotional lability, insomnia, poor concentration, paranoid delusion, recklessness, or withdrawal; a combination of two or more of these symptoms appears in most of the patients. Some patients may also show signs of sensory disturbance such as pain, paresthesia, and dysesthesia. The neurologic symptoms occur at least 6 months after the onset of psychiatric symptoms and include cerebellar ataxia, cognitive impairment, involuntary movements which may be dystonic, choreiform or myoclonic. Incontinence of urine, progressive immobility, and akinetic mutism are the late onset signs. Death often occurs because of intercurrent infections. The mean age at onset of symptoms is 29 years, and the progression or total duration of the disease spans 18 months in average, which is similar to that is reported for kuru and iCJD linked to treatment with hGH $[28,29,60]$. Generalized slowing of EEG activity and an increase in the levels of 14-3-3 protein in CSF may be diagnostic of vCJD in more than $50 \%$ of the cases. However, the observation of posterior thalamic high signals characterized by 'pulvinar' or 'hockey stick' signs on T2 diffusion or Flair weighted MRI imaging and the detection of $\mathrm{PrP}^{\text {res }}$ in tonsillar biopsy are important for the specific diagnosis of the disease $[29,70]$.

The neuropathalogical hallmark of vCJD is the presence of kuru-type amyloid plaques surrounded by spongiform lesions "the florid plaques" which also have been seen in scrapie but never in other human prion diseases $[28,29,60]$. Spongiform changes occur most evidently in the basal ganglia and thalamus with sparse distribution throughout the cerebral cortex. The florid plaques and $\operatorname{PrP}^{\text {res }}$ immunohistochemical staining have occurred predominantly in the cerebellum and cerebrum [28]. However, sufficient amounts of $\operatorname{PrP}^{\text {res }}$ are detected in the lymphoreticular system of vCJD patients [60]. The detection of $\mathrm{PrP}^{\mathrm{res}}$ in the lymphoreticular system has confidently been used for the diagnosis of vCJD even in clinically normal subjects (carriers) [71]. To date, all vCJD patients have been 129 MM homozygotes [72].

Very soon after the report on 10 vCJD cases, epidemiological studies, experimental transmission of the disease to cynomologous macaques and mice (wild as well as transgenic) and biochemical strain typing linked the etiology of VCJD to infection from BSE prions [60]. The same or diverse phenotypes may develop on primary and secondary transmission of $\mathrm{vCJD}$ and BSE to mice expressing human PrP, depending on the source of inoculum and the PrP sequence of the recipient, and the $129 \mathrm{MV}$ heterozygotes may be less resistant to vCJD transmission as compared to BSE transmission [73,74]. The E219K heterozygosity which has been considered a risk factor for transmission of BSE to humans may confer resistance to vCJD transmission within humans [70,75]. Moreover, at least 4 pathologically confirmed cases including 1 with subclinical or potentially preclinical infection have been associated with the secondary vCJD transmission via blood transfusion [76]. These reports on secondary iatrogenic transmission and the possibility of VCJD occurrence with long incubation periods in individuals with $129 \mathrm{MV}$ and $129 \mathrm{VV}$ PrP genotypes have raised serious public health concerns $[71,72,77,78]$. Some cases of kuru and iCJD have occurred after incubating the disease for almost 50 and 30 years, respectively $[63,64,76,79]$.

\section{Variably protease-sensitive prionopathy (VPSPr)}

In 2008, a novel form of atypical dementia was demonstrated in 11 patients, all of whom were $129 \mathrm{VV}$ homozygotes and most of whom revealed a positive family history for cognitive impairment. No mutation in PRNP additional to the M129V polymorphism was detected. The clinical course of the disease was 2 years longer than SCJD but neuropathological profiles were diagnostic of TSEs. A more distinctive feature based on which the disease was named initially as "protease-sensitive prionopathy" (PSPr) was the reduced resistance of $\operatorname{Pr} \mathrm{P}^{\mathrm{Dis}}$ isoforms to proteolysis by $\mathrm{PK}$. The proteolysis of $\operatorname{PrP}^{\mathrm{Dis}}$ isoforms by $\mathrm{PK}$ resulted in more than $3 \mathrm{PrP}^{\mathrm{Dis}}$ fragments. Amplification by PMCA and transmissibility to animal models of $\operatorname{PrP}^{\text {Dis }}$ yet remain to be investigated $[26,42]$. These studies will also inform on molecular mechanisms of the disease pathogenesis.

Similar to sCJD, PSPr can be seen in individuals harboring any of $3 \mathrm{M} 129 \mathrm{~V}$ genotypes (129 MM, $129 \mathrm{MV}$ and $129 \mathrm{VV}$ ). As the sensitivity of $\operatorname{PrP}^{\text {Dis }}$ isoforms to treatment with PK was variable according to the codon 129 genotype, the disease was renamed as "variably protease-sensitive prionopathy" (VPSPr). The $\operatorname{PrP}^{\text {Dis }}$ from $129 \mathrm{VV}$ cases was more sensitive to PK treatment than was $\mathrm{PrP}^{\mathrm{Dis}}$ from $129 \mathrm{MM}$ cases, with $\mathrm{PrP}^{\mathrm{Dis}}$ from 129 MV cases showing intermediary PK sensitivity [80]. Moreover, based on the codon 129 genotype, the $\operatorname{PrP}^{\text {Dis }}$ conformers from VPSPr cases not only showed differential immunoreativity to monoclonal antibodies raised against various PrP epitopes but also varied in the intensity (ratios) of individual fragments. Whether the codon 129 genotypes are associated with distinct clinical phenotypes, neuropathological lesions and histological distribution of $\operatorname{PrP}^{\text {Dis }}$ remains to be elucidated. To date, 30 
cases with VPSPr including 20 of $129 \mathrm{VV}, 7$ of $129 \mathrm{MV}$ and 3 of 129 MM PRNP genotype have been reported from various countries [42,80-82]. According to this data, the PRNP genotype 129 MM appears protective against the development of VPSPr [42].

\section{Conclusion}

The epidemics of kuru, iatrogenic CJD and vCJD have reached their end [83]. However, sporadic and genetic cases of human prion diseases are occurring worldwide with an annual prevalence of 1-2 cases per million of population. Among genetic human prion diseases, GSS presents predominantly as an amyloidopathy. There is no cure for these disorders. Most of developing countries including Pakistan have no epidemiological information on human prion diseases. We have recently performed the analysis of PRNP in 909 unrelated Pakistani individuals. An insertion of 3 octapeptide repeats (3-OPRI) was found in heterozygous state in an individual and the extent of homozygosity at the 129 codon was $63 \%$. These results indicate that Pakistani population is susceptible to prion disorders [84]. The octapeptide repeats region of human PRNP consists of 5 repeats which are designated as $\mathrm{R} 1$ through $\mathrm{R} 5$. If any nucleotide variation is found within a repeat, the name of that nucleotide is added to the name of corresponding repeat i.e., R2a or R3g [85]. A 3-OPRI (R1, R2, R2, R3g, R2, R2, R3, R4) linked to $219 \mathrm{~K}$ allele in one person (68 years old) and to $129 \mathrm{~V}$ allele in another (69 years old) has been associated with f/gCJD $[86,87]$. A 3OPRI (R1, R2, R2, R2a, R2, R2, R3, R4) linked to 129 M allele has also been detected in a clinically normal Chinese young girl and her mother who was in her late 30's [85].

\footnotetext{
Abbreviations

PRNP: Prion protein gene; PrP: Prion protein; $\operatorname{PrP}^{\complement}$ : Cellular isoform of prion protein; PrPSc: Scrapie isoform of prion protein; $\operatorname{PrP}^{\mathrm{M}}$ : Mutant PrP; TSE(s): Transmissible spongiform encephalopathy(ies); CJD: Cruetzfeldt-Jacob disease; sCJD: Sporadic CJD; vCJD: Variant CJD; f/gCJD: Familial/genetic CJD; iCJD: latrogenic CJD; FFI: Fatal familial insomnia; GSS: Gertsmann-StrausslerScheinker syndrome; sFI: Sporadic fatal insomnia; PSPr: Protease-sensitive prionopathy; VPSPr: Variably protease-sensitive prionopathy; TME: Transmissible mink encephalopathy; CWD: Chronic wasting disease; BSE: Bovine spongiform encephalopathy; EUE: Exotic ungulate spongiform encephalopathy; FSE: Feline spongiform encephalopathy; NHP: TSE in nonhuman primates; OPR: Octapeptide repeats; OPRI: Insertion of octapeptide repeats; OPRD: Deletion of octapeptide repeats; GPI: Glycosylphosphatidylinositol; CNS: Central nervous system; EEG: Electroencephalography; CSF: Cerebrospinal fluid; CT: Computer tomography; MRI: Magnetic resonance imaging; PET: Positron emission tomography; PK: Proteinase K; cDNA: Complementary DNA; hGH: Human growth hormone; res: Resistant; Dis: Disease; kb: Kilo bases; kDa: Kilo Daltons; aa: Amino acids; A: Alanine; D: Aspartic acid; E: Glutamic acid; F: Phenylalanine; G: Glysine; H: Histidine; I: Isoleucine; K: Lysine; L: Leucine; M: Methionine; N: Asparagine; P: Proline; Q: Glutamine; R: Arginine; S: Serine; T: Threonine; V: Valine; W: Tryptophan; X: Stop codon; Y: Tyrosine.
}

\section{Author details}

${ }^{1}$ Department of Physiology and Cell Biology, Centre for Research in Endocrinology and Reproductive Sciences (CRERS), University of Health Sciences (UHS), Khayaban-e-Jamia Punjab, Lahore 54600, Pakistan. ${ }^{2}$ Department of Human Genetics and Molecular Biology, University of Health Sciences (UHS), Khayaban-e-Jamia Punjab, Lahore 54600, Pakistan.

\section{Authors' contributions}

$\mathrm{MI}^{1}$ surveyed literature and wrote the article. $\mathrm{SM}^{2}$ organized the contents and submitted the article. All authors read and approved the final manuscript.

\section{Competing interests}

The authors declare that they have no competing interests.

Received: 4 August 2011 Accepted: 24 December 2011

Published: 24 December 2011

\section{References}

1. Linden R, Martins VR, Prado MAM, Cammarota M, Izquierdo I, Brentani RR: Physiology of the prion protein. Physiol Rev 2008, 88:673-728.

2. Pan KM, Baldwin M, Nguyen J, Gasset M, Serban A, Groth D, Mehlhorn I, Huang Z, Fletterick RJ, Cohen FE, Prusiner SB: Conversion of alpha-helices into beta-sheets features in the formation of the scrapie prion proteins. Proc Natl Acad Sci USA 1993, 90:10962-10966.

3. Prusiner SB: Prions. Proc Natl Acad Sci USA 1998, 95:13363-13383.

4. Smirnovas V, Baron GS, Offerdahl DK, Raymond GJ, Caughey B, Surewicz WK: Structural organization of brain-derived mammalian prions examined by hydrogen-deuterium exchange. Nat Struct Mol Biol 2011, 18:504-506.

5. Zahn R, Liu A, Luhrs T, Riek R, von Schroetter C, Lopez Garcia F, Billeter M, Calzolai $L$, Wider $G$, Wuthrich $K$ : NMR solution structure of the human prion protein. Proc Natl Acad Sci USA 2000, 97:145-150.

6. Collinge J, Clarke AR: A general model of prion strains and their pathogenicity. Science 2007, 318:930-936.

7. Aguzzi A: Prion diseases of humans and farm animals: epidemiology, genetics, and pathogenesis. J Neurochem 2006, 97:1726-1739.

8. Imran M, Mahmood S: An overview of animal prion diseases. Virol J 2011, 8:493.

9. Marsh RF, Hadlow WJ: Transmissible mink encephalopathy. Rev Sci Tech 1992, 11:539-550.

10. Sigurdson CJ, Miller MW: Other animal prion diseases. Brit Med Bull 2003, 66:199-212.

11. Williams ES, Young S: Chronic wasting disease of captive mule deer: a spongiform encephalopathy. J Wildl Dis 1980, 16:89-98.

12. Wells GAH, Scott $A C$, Johnson $C T$, Gunning RF, Hancock RD, Jeffrey M Dawson M, Bradley R: A novel progressive spongiform encephalopathy in cattle. Vet Rec 1987, 121:419-420.

13. Kirkwood JK, Cunningham AA, Wells GA, Wilesmith JW, Barnett JE: Spongiform encephalopathy in a herd of greater kudu (Tragelaphus strepsiceros): epidemiological observations. Vet Rec 1993, 133:360-364.

14. Kirkwood JK, Cunningham AA: Epidemiological observations on spongiform encephalopathies in captive wild animals in the British Isles. Vet Rec 1994, 135:296-303.

15. Wyatt JM, Pearson GR, Gruffydd-Jones TJ: Feline spongiform encephalopathy. Feline Pract 1993, 21:7-9.

16. Bons N, Mestre-Frances N, Belli P, Cathala F, Gajdusek DC, Brown P: Natural and experimental oral infection of nonhuman primates by bovine spongiform encephalopathy agents. Proc Natl Acad Sci USA 1999, 96:4046-4051.

17. Gajdusek DC, Zigas V: Degenerative disease of the central nervous system in New Guinea. The endemic occurrence of "kuru" in the native population. New Engl J Med 1957, 257:974-978.

18. Creutzfeldt HG: U" ber eine eigenartige herdfo"rmige Erkrankung des Zentralnervensystems. Z Gesamte Neurol Psychiatr 1920, 57:1-19.

19. Jakob $A: U^{\prime \prime}$ ber eigenartige Erkrankungen des Zentralnervensystems mit bemerkenswertem anatomischem. Befunde. (Spastische PseudoskleroseEncephalomyelopathie mit disseminierten Degenerationsherden). Z Gesamte Neurol Psychiatr 1921, 64:147-228. 
20. Kirschbaum WR: Zwei eigenartige Erkrankung des Zentralnervensystems nach Art der spatischen Pseudosklerose (Jakob). Z Neurol Pyschiatry 1924, 92:175-220.

21. Richardson EP, Masters CL: The nosology of Creutzfeldt-Jakob disease and conditions related to the accumulation of PrPCJD in the nervous system. Brain Pathol 1995, 5:33-41.

22. Duffy P, Wolf J, Collins G, DeVoe AG, Streeten B, Cowen D: Possible person-to-person transmission of Creutzfeldt-Jakob disease. N Engl J Med 1974, 290:692-693.

23. Lugaresi E, Medori R, Montagna P, Baruzzi A, Cortelli P, Lugaresi A, Tinuper P, Zucconi M, Gambetti P: Fatal familial insomnia and dysautonomia with selective degeneration of thalamic nuclei. $N$ Engl J Med 1986, 315:997-1003

24. Will RG, Ironside JW, Zeidler M, Cousens SM, Estibeiro K, Alperovitch A Poser S, Pocchiari M, Hofman A, Smith PG: A new variant of CreutzfeldtJakob disease in the UK. Lancet 1996, 347:921-925.

25. Mastrianni JA, Nixon R, Layzer R, Telling GC, Han D, DeArmond SJ, Prusiner SB: Prion protein conformation in a patient with sporadic fatal insomnia. N Engl J Med 1999, 340:1630-1638.

26. Gambetti $P$, Dong Z, Yuan J, Xiao X, Zheng M, Alshekhlee A, Castellani R, Cohen M, Barria MA, Gonzalez-Romero D, Belay ED, Schonberger LB, Marder K, Harris C, Burke JR, Montine T, Wisniewski T, Dickson DW, Soto C Hulette CM, Mastrianni JA, Kong Q, Zou WQ: A novel human disease with abnormal prion protein sensitive to protease. Ann Neurol 2008, 63:697-708.

27. Mead S, Stumpf MP, Whitfield J, Beck J, Poulter M, Campbell T, Uphill J, Goldstein D, Alpers MP, Fisher E, Collinge J: Balancing selection at the prion protein gene consistent with prehistoric kurulike epidemics. Science 2003, 300:640-643.

28. Belay ED: Transmissible spongiform encephalopathies in humans. Annu Rev Microbiol 1999, 53:283-314.

29. Brandel JP: Transmissible spongiform encephalopathies. Orphanet Encyclopedia 2004, 1-7[http://www.orpha.net/data/patho/GB/uk-TSE.pdf].

30. Kawauchi Y, Kamitani T, Yagishita S, Kitamoto T, Kishida H: Autopsy case of Creutzfeldt-Jakob disease with Met/Val heterozygosity at codon 129 and type 1 protease-resistant prion protein presenting some florid-type plaques and many Kuru plaques in the cerebellum. Neuropathology 2006, 26:313-317.

31. Cornelius JR, Boes CJ, Ghearing G, Leavitt JA, Kumar N: Visual symptoms in the Heidenhain variant of Creutzfeldt-Jakob Disease. J Neuroimaging 2009, 19:283-287.

32. Parchi P, Strammiello $R$, Giese A, Kretzschmar $H$ : Phenotypic variability of sporadic human prion disease and its molecular basis: past, present, and future. Acta Neuropathol 2011, 121:91-112.

33. Court L, Bert J: Electrophysiologie des encéphalopathies transmissibles. Path Biol 1995, 43:25-42.

34. Bratosiewicz-Wasik J, Liberski PP, Golanska E, Jansen GH, Wasik TJ: Regulatory sequences of the PRNP gene influence susceptibility to sporadic Creutzfeldt-Jakob disease. Neurosci Lett 2007, 411:163-167.

35. Mead S, Mahal SP, Beck J, Campbell T, Farrall M, Fisher E, Collinge J: Sporadic-but not variant-Creutzfeldt-Jakob disease is associated with polymorphisms upstream of PRNP exon 1. Am J Hum Genet 2001, 69:1225-1235.

36. Palmer MS, Dryden AJ, Hughes JT, Collinge J: Homozygous prion protein genotype predisposes to sporadic Creutzfeldt-Jakob disease. Nature 1991, 352:340-342.

37. Windl O, Dempster M, Estibeiro JP, Lathe R, De Silva R, Esmonde T, Will R, Springbett A, Campbell TA, Sidle KCL, Palmer MS, Collinge J: Genetic basis of Creutzfeldt-Jakob disease in the United Kingom: a systematic analysis of predisposing mutations and allelic variation in the PRNP gene. Hum Genet 1996, 98:259-264.

38. Shibuya S, Higuchi J, Shin R-W, Tateishi J, Kitamoto T: Protective prion protein polymorphisms against sporadic Creutzfeldt-Jakob disease. Lancet 1998, 351:419.

39. Shibuya S, Higuchi J, Shin RW, Tateishi J, Kitamoto T: Codon 219 Lys allele of PRNP is not found in sporadic Creutzfeldt-Jakob disease. Ann Neurol 1998, 43:826-828.

40. Soldevila M, Calafell F, Andrés AM, Yagüe J, Helgason A, Stefánsson K, Bertranpetit J: Prion susceptibility and protective alleles exhibit marked geographic differences. Hum Mutat 2003, 22:104-104.
41. Brandner S: Diversity of prion diseases: (no) strains attached? Acta Neuropathol 2011, 121:1-4.

42. Gambetti P, Cali I, Notari S, Kong Q, Zou WQ, Surewicz WK: Molecular biology and pathology of prion strains in sporadic human prion diseases. Acta Neuropathol 2011, 121:79-90.

43. Wadsworth JDF, Collinge J: Molecular pathology of human prion disease. Acta Neuropathol 2011, 121:69-77.

44. Capellari S, Strammiello R, Saverioni D, Kretzschmar H, Parchi P: Genetic Creutzfeldt-Jakob disease and fatal familial insomnia: insights into phenotypic variability and disease pathogenesis. Acta Neuropathol 2011, 121:21-37.

45. Montagna $P$, Gambetti $P$, Cortelli $P$, Lugaresi E: Familial and sporadic fatal insomnia. Lancet Neurol 2003, 2:167-176.

46. Baldin E, Capellari C, Provini F, Corrado P, Liguori R, Parchi P, Montagna P, Cortelli P: A case of fatal familial insomnia in Africa. J Neurol 2009, 256:778-1779.

47. Gambetti P, Kong Q, Zou W, Parchi P, Chen SG: Sporadic and familial CJD: classification and characterization. Brit Med Bull 2003, 66:213-239.

48. Parchi P, Capellari S, Chin S, Schwarz HB, Schecter NP, Butts JD, Hudkins P, Burns DK, Powers JM, Gambetti P: A subtype of sporadic prion disease mimicking fatal familial insomnia. Neurology 1999, 52:1757-1763.

49. Priano L, Giaccone G, Mangieri M, Albani G, Limido L, Brioschi A, Pradotto L, Orsi L, Mortara P, Fociani P, Mauro A, Tagliavini F: An atypical case of sporadic fatal insomnia. J Neurol Neurosurg Psychiatry 2009, 80:924-927.

50. Kretzschmar HA, Stowring LE, Westaway D, Stubblebine WH, Prusiner SB, Dearmond SJ: Molecular cloning of a human prion protein CDNA. DNA 1986, 5:315-324.

51. Nozaki I, Hamaguchi T, Sanjo N, Noguchi-Shinohara M, Sakai K, Nakamura Y, Sato T, Kitamoto T, Mizusawa H, Moriwaka F, Shiga $Y$, Kuroiwa $Y$, Nishizawa M, Kuzuhara S, Inuzuka T, Takeda M, Kuroda S, Abe K, Murai H, Murayama S, Tateishi J, Takumi I, Shirabe S, Harada M, Sadakane A, Yamada M: Prospective 10-year surveillance of human prion diseases in Japan. Brain 2010, 133:3043-3057.

52. Corsaro A, Thellung S, Bucciarelli T, Scotti L, Chiovitti K, Villa V, D'Arrigo C, Aceto A, Florio T: High hydrophobic amino acid exposure is responsible of the neurotoxic effects induced by E200K or D202N disease-related mutations of the human prion protein. Int J Biochem Cell Biol 2011, 43:372-382.

53. Nitrini $R$, Rosemberg $S$, Passos-Bueno $M R$, Teixeira da Silva $L S$, lughetti $P$, Papadopoulos M, Carrilho PM, Caramelli P, Al- brecht S, Zatz M, LeBlanc A Familial spongiform encephalopathy with distinct clinico-pathological features associated with a novel prion gene mutation at codon 183. Ann Neurol 1997, 42:138-146.

54. Takazawa T, Ikeda K, Ito H, Aoyagi J, Nakamura Y, Miura K, Iwamoto K, Kano O, Kawabe K, Iwasaki Y: A distinct phenotype of leg hyperreflexia in a Japanese family with Gerstmann-Sträussler-Scheinker syndrome (P102L). Intern Med 2010, 49:339-342.

55. Provini F, Vetrugno R, Pierangeli G, Cortelli P, Rizzo G, Filla A, Strisciuglio C, Gallassi R, Montagna P: Sleep and temperature rhythms in two sisters with P102L Gerstmann-Stra"ussler-Scheinker (GSS) disease. Sleep Med 2009, 10:374-377.

56. Bianca M, Bianca S, Vecchio I, Raffaele R, Ingegnosi C, Nicoletti F: Gerstmann-Sträussler-Scheinker disease with P102L-V129 mutation: a case with psychiatric manifestations at onset. Ann Genet 2003, 46:467-469.

57. Jansen C, Parchi P, Capellari S, Vermeij AJ, Corrado P, Baas F, Strammiello R, van Gool WA, van Swieten JC, Rozemuller AJ: Prion protein amyloidosis with divergent phenotype associated with two novel nonsense mutations in PRNP. Acta Neuropathol 2010, 119:189-197.

58. Alzualde A, Indakoetxea B, Ferrer I, Moreno F, Barandiaran M, Gorostidi A, Estanga A, Ruiz I, Calero M, van Leeuwen FW, Atares B, Juste R, RodriguezMartínez AB, López de Munain A: A novel PRNP Y218N mutation in Gerstmann-Sträussler-Scheinker disease with neurofibrillary degeneration. J Neuropathol Exp Neurol 2010, 69:789-800.

59. Liberski PP, Brown P: Kuru: its ramifications after fifty years. Exp Gerontol 2009, 44:63-69

60. Will RG: Acquired prion disease: iatrogenic CJD, variant CJD, kuru. Brit Med Bull 2003, 66:255-265.

61. Collinge J, Palmer MS, Dryden AJ: Genetic predisposition to iatrogenic Creutzfeldt-Jakob disease. Lancet 1991, 337:1441-1442.

62. Gajdusek DC, Gibbs CJ, Alpers M: Experimental transmission of a kuru-like syndrome to chimpanzee. Nature 1966, 209:794-796. 
63. Brandner S, Whitfield J, Boone K, Puwa A, O'Malley C, Linehan JM, Joiner S, Scaravilli F, Calder I, Alpers MP, Wadsworth JDF, Collinge J: Central and peripheral pathology of kuru: pathological analysis of a recent case and comparison with other forms of human prion disease. Phil Trans $R$ Soc $B$ 2008, 363:3755-3763

64. Collinge J, Whitfield J, McKintosh E, Beck J, Mead S, Thomas DJ, Alpers MP Kuru in the 21st century - an acquired human prion disease with very long incubation periods. Lancet 2006, 367:2068-2074.

65. Mead S, Whitfield J, Poulter M, Shah P, Uphill J, Campbell T, Al-Dujaily H, Hummerich H, Beck J, Mein CA, Verzilli C, Whittaker J, Alpers MP, Collinge J: A novel protective prion protein variant that colocalizes with Kuru exposure. N Engl J Med 2009, 361:2056-2065.

66. Wadsworth JDF, Joiner S, Linehan JM, Desbruslais M, Fox K, Cooper S, Cronier S, Asante EA, Mead S, Brandner S, Hill AF, Collinge J: Kuru prions and sporadic Creutzfeldt-Jakob disease prions have equivalent transmission properties in transgenic and wild-type mice. Proc Nat Acad Sci USA 2008, 105:3885-3890.

67. Manuelidis L, Chakrabarty T, Miyazawa K, Nduom NA, Emmerling K: The kuru infectious agent is a unique geographic isolate distinct from Creutzfeldt-Jakob disease and scrapie agents. Proc Natl Acad Sci USA 2009, 106:13529-13534

68. Manuelidis L: Transmissible encephalopathy agents: virulence, geography and clockwork. Virulence 2010, 1:101-104.

69. Beekes M: Variant Creutzfeldt-Jakob disease (vCJD): epidemiology and prevention from human to human secondary transmission. Bundesgesundheitsblatt Gesundheitsforschung Gesundheitsschutz 2010, 53:597-605.

70. Lukic A, Beck J, Joiner S, Fearnley J, Sturman S, Brandner S, Wadsworth JD, Collinge J, Mead S: Heterozygosity at polymorphic codon 219 in variant Creutzfeldt-Jakob disease. Arch Neurol 2010, 67:1021-1023.

71. Ironside JW, Bishop MT, Connolly K, Hegazy D, Lowrie S, Le Grice M, Ritchie DL, McCardle LM, Hilton DA: Variant Creutzfeldt-Jakob disease: prion protein genotype analysis of positive appendix tissue samples from a retrospective prevalence study. BMJ 2006, 332:1164-1165.

72. Bishop MT, Pennington C, Heath CA, Will RG, Knight RS: PRNP variation in UK sporadic and variant Creutzfeldt Jakob disease highlights genetic risk factors and a novel non-synonymous polymorphism. BMC Med Genet 2009, 10:146.

73. Wadsworth JDF, Asante EA, Desbruslais M, Linehan JM, Joiner S, Gowland I, Welch J, Stone L, Lloyd SE, Hill AF, Brandner S, Collinge J: Human prion protein with valine 129 prevents expression of variant CJD phenotype. Science 2004, 306:1793-1796.

74. Asante EA, Linehan JM, Gowland I, Joiner S, Fox K, Cooper S, Osiguwa O, Gorry M, Welch J, Houghton R, Desbruslais M, Brandner S, Wadsworth JDF, Collinge J: Dissociation of pathological and molecular phenotype of variant Creutzfeldt-Jakob disease in transgenic human prion protein 129 heterozygous mice. Proc Natl Acad Sci USA 2006, 103:10759-10764.

75. Hizume M, Kobayashi A, Teruya K, Ohashi H, Ironside JW, Mohri S, Kitamoto T: Human prion protein (PrP) $219 \mathrm{~K}$ is converted to PrPSc but shows heterozygous inhibition in variant Creutzfeldt-Jakob disease infection. J Biol Chem 2009, 284:3603-3609.

76. Wroe SJ, Pal S, Siddique D, Hyare H, Macfarlane R, Joiner S, Linehan JM, Brandner S, Wadsworth JD, Hewitt P, Collinge J: Clinical presentation and pre-mortem diagnosis of variant Creutzfeldt-Jakob disease associated with blood transfusion: a case report. Lancet 2006, 368:2061-2067.

77. Wilson $\mathrm{K}$, Ricketts MN: A new human genotype prone to variant Creutzfeldt-Jakob disease. BMJ 2006, 332:1164-1165.

78. Kaski D, Mead S, Hyare H, Cooper S, Jampana R, Overell J, Knight R, Collinge J, Rudge P: Variant CJD in an individual heterozygous for PRNP codon 129. Lancet 2009, 374:2128.

79. Brown P, Preece M, Brandel JP, Sato T, McShane L, Zerr I, Fletcher A, Will RG, Pocchiari , Cashman NR, d'Aignaux JH, Cervena'kova' L, Fradkin J, Schonberger LB, Collins SJ: latrogenic Creutzfeldt-Jakob disease at the millennium. Neurology 2000, 55:1075-1081.

80. Zou WQ, Puoti G, Xiao X, Yuan J, Qing L, Cali I, Shimoji M, Langeveld JP, Castellani R, Notari S, Crain B, Schmidt RE, Geschwind M, Dearmond SJ, Cairns NJ, Dickson D, Honig L, Torres JM, Mastrianni J, Capellari S, Giaccone G, Belay ED, Schonberger LB, Cohen M, Perry G, Kong Q, Parchi P, Tagliavini F, Gambetti P: Variably protease-sensitive prionopathy: a new sporadic disease of the prion protein. Ann Neurol 2010, 68:162-172.
81. Jansen C, Head MW, van Gool WA, Baas F, Yull H, Ironside JW, Rozemuller AJ: The first case of protease-sensitive prionopathy (PSPr) in The Netherlands: a patient with an unusual GSS-like clinical phenotype. J Neurol Neurosurg Psychiatry 2010, 81:1052-1055.

82. Rodríguez-Martínez AB, Garrido JM, Zarranz JJ, Arteagoitia JM, de Pancorbo MM, Atarés B, Bilbao MJ, Ferrer I, Juste RA: A novel form of human disease with a protease-sensitive prion protein and heterozygosity methionine/valine at codon 129: case report. BMC Neurol 2010, 10:99.

83. Norrby E: Prions and protein-folding diseases. J Intern Med 2011, 270:1-14.

84. Imran M, Mahmood S, Hussain R, Abid NB, Lone KP: Frequency distribution of PRNP polymorphisms in the Pakistani population. Gene 2012, 492:186-194.

85. Yu SL, Jin L, Sy MS, Mei FH, Kang SL, Sun GH, Tien P, Wang FS, Xiao GF: Polymorphisms of the PRNP gene in Chinese populations and the identification of a novel insertion mutation. Eur J Hum Genet 2004, 12:867-870.

86. Grasbon-Frodl E, Schmalzbauer R, Weber P, Krebs B, Windl O, Zerr I, Kretzschmar HA: A novel three extra-repeat insertion in the prion protein gene (PRNP) in a patient with Creutzfeldt-Jakob disease. Neurogenetics 2004, 5:249-250.

87. Nishida Y, Sodeyama N, Toru Y, Toru S, Kitamoto T, Mizusawa H: A case of Creutzfeldt-Jakob disease with a novel insertion mutation and codon 219 Lysine/Lysine polymorphism in the prion protein gene. Prions 2005, 251-252.

doi:10.1186/1743-422X-8-559

Cite this article as: Imran and Mahmood: An overview of human prion diseases. Virology Journal 2011 8:559.

\section{Submit your next manuscript to BioMed Central and take full advantage of:}

- Convenient online submission

- Thorough peer review

- No space constraints or color figure charges

- Immediate publication on acceptance

- Inclusion in PubMed, CAS, Scopus and Google Scholar

- Research which is freely available for redistribution

Submit your manuscript at www.biomedcentral.com/submit
C) Biomed Central 